\title{
Libro de la manzana - De la muerte de Aristóteles y Prólogo de Manfredo, príncipe de 'Tárento
}

Resumen

Julio Picasso nos presenta una nueva traducción: el cuento del Libro de la manzana o La muerte de Aristóteles, que fue escrito en Mesopotamia durante el s. IX. Se trata de la primera traducción al espańol y, además, completa, de la traducción latina de Manfredo.

Palabras clave: Aristóteles, Manfredo, Mesopotamia

Abstract

Julio Picasso presents us a new translation: Libro de la manzana or Aristotles death's tale, written in Mesopotamia on s. IX. It's the first Spanish and complete translation from the latin Manfredo.

Key words: Aristotle, Manfredo, Mesopotamia

Cárabe, existen tres versiones con el nombre de Kitab at-Tuffaha. Cuatro siglos después se lo tradujo al persa y después al hebreo. El título persa fue Tarjuma-i-Makala-i-Arastatalis. De aquí fue traducido al inglés por Margoliouth (1892). La traducción al hebreo fue realizada por Abrahán ha-Levi ibn Chasdai de Barcelona (entre 1235 y 1240), quizá en la misma corte de Palermo, y llevó el nombre de Sefer Hat-Tappuaj. Por 1255 Manfredo, hijo 


\section{JULIO PICASSO MUÑOZ}

del emperador Federico II, stupor mundi, vertió esta traducción hebrea al latín, añadiendo un prólogo propio. Esta traslación latina fue traducida parcialmente al francés (1844) por Huillard-Breholles. Hertz (1905) volvió a realizar otra traducción parcial al alemán. La nuestra es la primera traducción al español y, además, completa, de la traducción latina de Manfredo.

De la traducción hebrea de ibn Chasdai se realizaron otras tres traducciones modernas: al latín por Losius (1706), al alemán por Musen (1873) y al inglés por Kalish (1885).

Federico II y sus hijos pasaron su vida peleando con los papas, inquietos de que los Hohenstaufen dominaran en los territorios al norte y al sur de los Estados Pontificios. Llovieron de la corte papal las excomuniones y las campañas satanizantes contra Federico II y sus hijos. Esto explica que encontremos al emperador en el círculo de los herejes en el Infierno de Dante, mas el poeta trató de manera muy diferente a Manfredo. A pesar de haber muerto en la batalla de Benevento (1266) y excomulgado dos veces, Dante supuso en Manfredo una conversión in articulo mortis. Es así como aparece en el primer grupo de gente, los excomulgados, del Antepurgatorio con la misma descripción con que I Sam presenta a David: biondo era e bello e di gentile aspetto (Pg. III, 107): era rubio y bello, de noble aspecto. Este episodio de la Comedia dio más fama al desventurado joven que todas sus hazañas.

No es de extrañar que Manfredo supiese hebreo pues muchos doctos judíos y árabes, provenientes especialmente de España, poblaban sin problemas la corte palermitana. Es probable que Manfredo tradujera en 1255 el Libro de la Manzana en Lucera, protegido por los sarracenos de su padre, después de haber batido a las tropas pontificales en Foggia. Su prólogo y la traducción pecan por confusas y enredadas, como el lector podrá apreciar, pero el cuento en sí es traducible y podemos salvar su sana ingenuidad y su ternura.

Hemos utilizado la edición de Mazzantini (1990). 


\section{Prólogo DE Mantredo}

Como el hombre, la más digna de todas las criaturas, fue creado a imagen y semejanza de Dios, y como todo lo noble fue creado por lo innoble, ${ }^{1}$ no hay nada más noble que él pueda hacer que conocerse a sí mismo y a su Creador, así como no hay nada más condenable que ignorar ambas cosas y entregarse únicamente a las cosas sensibles. Pues aunque (el hombre) recibe la iluminación con relación primera y última por el primero (Dios), que ilumina a todo hombre que viene a este mundo y nos ha marcado con la luz de su rostro, para que (el hombre) pueda llegar a Dios, fuente de la verdadera luz, fin suyo, a semejanza del sol, que nace y muere y regresa a su lugar, sin embargo es impedido por la oscuridad de su sometida cónyuge, ${ }^{2}$ de la que se adquiere toda enfermedad de corrupción, de tal manera que, deformado por el vicio de la concupiscencia terrenal, semejante al asno, nada entiende $y$, con la memoria confundida en él de su propio honor, no admite el juicio de elección de las cosas honorables, sino que, extraviado por las tinieblas de la ignorancia, no alcanza el término de su propia perfección al que su voluntad tendía; así, pues, se está remoto o cercano de Dios según su propia ciencia o ignorancia. Por lo cual, para que se levante de este extraviado error y sea educado, para que (salga) de la densidad palpable de las tinieblas del cuerpo y encuentre el camino de la vida de la que se desvió miserablemente, y para que dirija sus ojos, acostumbrados a las tinieblas, hacia la luz de la diáfana verdad, conviene que (el hombre) sea ilustrado con los esplendores de las doctrinas humanas y, por medio de estas, conozca la sublimidad del sumo Creador del universo; que lo estudie con atención ininterrumpida; que se considere noble e innoble; que reprima sus vicios a fin de que, venciendo las fuerzas del cuerpo por medio de las ciencias, se haga, con el cumplimiento de las virtudes, semejante a su principio y beba sin cesar del consuelo de la eternidad.

En efecto, el camino de la vida sería impracticable a muchos si los sabios no hubiesen corregido los vicios de los hombres en las demostraciones de las doctrinas; si no les hubiesen prendido la lumbrera de la verdad en la cárcel de este cuerpo; y si, presentándose a sí mismos como ejemplos, no hubiesen conducido a muchos hombres _ en nada diferentes de las bestias porque se encaminaban licenciosamente con apetito bestial hacia los placeres — a despreciar las cosas mortales, que no duran nada, y a honrar y a temer a Dios. Más bien, por esto, aplicados a las virtudes, aprendieron a castigar con el freno de la moderación la 


\section{JULIO PICASSO MUÑOZ}

lubricidad del cuerpo para que deseasen ser liberados ya de la masa del cuerpo; para que no temiesen morir y, elevados de las borrascas del mundo, sostenidos con el gran privilegio de una comprobada seguridad y de una felicidad indubitable, se encaminasen a la perfección de su deseo con mucha vehemencia.

Por lo cual, Yo, Manfredo, hijo del Divino Augusto Emperador Federico, Príncipe de Tárento por la gracia de Dios, Señor del Honor del Monte Sant'Angelo ${ }^{3}$ y Baile General del Rey Ilustre Conrado II en el Reino de Sicilia, estando postrado bajo accidentes de la fragilidad humana a causa de la discordia de los elementos concordes, de los que nos componemos como el resto de la gente; y estando tan demacrado nuestro cuerpo por la molestia de una grave enfermedad que ya no pensaba poder vivir en el cuerpo por más tiempo; y estando tan angustiados los que asistían a mi dolencia que juzgaban que yo tenía miedo de la inminencia de la muerte; pero considerando con atenta mente los documentos teológicos filosóficos que una muchedumbre de sabios venerables me habían enseñado en el palacio imperial del Divino Augusto Emperador Serenísimo, mi señor padre, sobre la naturaleza del mundo, el flujo de los cuerpos, ${ }^{4}$ la creación de las almas, la eternidad y perfección de las mismas, la inconsistencia de las cosas materiales y la consistencia de las formas que no siguen al naufragio o a la deficiencia de su materia, no me lamentaba tanto a causa de mi disolución — como era opinión de ellos — cuanto a causa de que, para poseer el premio de nuestra perfección, no reposaba en la justicia por mis méritos sino únicamente en la misericordia del Creador.

En estas circunstancias cayó en mis manos un libro llamado De la manzana de Aristóteles, el príncipe de los filósofos, editado por él al dejar su vida, en el que prueba que los sabios no se duelen de la partida de su albergue de arcilla, sino que corren gozosos hacia el premio de la perfección, por el que huyeron totalmente de las cargas del siglo, no escatimaron esfuerzos en dedicar su tiempo y su vida a las grandes labores de sus estudios. A los presentes ordené que leyeran este libro para que aprendieran allí que yo no me lamentaba por morir de mi enfermedad. Como este libro no se encontraba entre los cristianos, porque lo leímos en hebreo, traducido al hebreo del árabe, lo traduje, al restablecerse mi salud, de la lengua hebrea al latín para la enseñanza de muchos. En él el compilador incluye algunos diálogos porque Aristóteles no escribió dicho libro, sino que existe escrito por unas personas que quisieron aprender la causa de su alegría al morir, como se trata en el desarrollo del libro. 


\section{IIBRO DE IA MANZFNA O}

\section{DE IA MUERTE DE ARTSOLTEISS}

Omo estaba cerrado el camino de la verdad para los sabios y obstruido el camino
de la rectitud para los intelectos, unos sabios se reunieron en una casa y, unánimes, decidieron precisar y entender el camino de la rectitud por el que los hombres pudieran vivir; y solo encontraron un camino, que era: que el hombre quiera para el prójimo lo que quiere para sí mismo; que se sustraiga de cosas vergonzosas; que profese la verdad; que derive su juicio de sí mismo; y que tema a su Creador.

1. Hubo en aquel tiempo un grande, famoso e inteligente sabio cuyo nombre era Aristóteles; y todos los sabios de su tiempo escuchaban sus enseñanzas, atendían sus lecciones y aprendían de él. Y como se había acercado el momento de su deceso y sufría de la enfermedad que acarrearía su muerte, todos los sabios se reunieron y fueron a verlo y a conocer las causas de su enfermedad. Lo encontraron con una manzana en la mano a la que olía. Estaba muy demacrado por la vehemencia de la enfermedad, afligido por el dolor de la muerte. Ellos, al verlo así, se turbaron mucho y se acercaron a él, y al aproximarse, encontraron que su rostro estaba brillante, y él mismo, alegre. Él se adelantó a saludarlos, y entonces le dijeron:

-Oh señor y maestro nuestro, al comienzo cuando te vimos, el alma nos abandonó y nos turbamos porque nos dimos cuenta de la violenta enfermedad que te abruma y de tu muy debilitada salud, pero al verte contento y tu rostro brillante, nuestro espíritu, que había partido, regresó a su sitio.

Aristóteles se burló de ellos diciendo:

-No penséis en vuestros corazones que yo me alegro porque espero librarme de la gran enfermedad que tengo, ya que bien sé ahora que estoy a punto de morir y que no puedo librarme (de ella) porque el dolor ha crecido mucho, y si no fuera por esta manzana que en mi mano tengo y cuyo olor me reconforta y prolonga un poco mi vida, ya habría expirado. Pero el alma «sensible», por la que somos comunes con las bestias, goza con su buen olor, y además yo estoy muy alegre porque me retiro de este mundo. Esto sucede con los contrarios, 


\section{JULIO PICASSO MUÑOZ}

ya que los cuatro elementos, de los que se crea todo lo creado que está bajo el sol, son contrarios entre sí; porque uno es frío, otro caliente, uno seco, otro húmedo. ¿Y cómo podría perdurar un cuerpo compuesto de tales elementos o permanecer en vida sino muy poco? Pero cuando todos estos elementos están en igualdad, y uno no contraría al otro ni domina a su contrario, entonces la vida es cómoda y se puede existir y vivir; y cuando uno domina a otro, disminuye y debilita a su contrario, entonces sobreviene la enfermedad. Y si se encuentra algún médico tan sabio que conozca la enfermedad como para que fortifique los elementos débiles y debilite los fortificados, entonces él reconduce el cuerpo a su salud y este puede convalecer de su enfermedad. Pero hay muchos de ellos que ignoran y no saben de qué se trata, y agravan la enfermedad y hacen que el cuerpo se deslice a su pérdida y a su muerte. Pero el alma «inteligible» tiene debajo de sí a las (otras) almas y las domina; y ella no es compuesta, sino que es de un solo elemento simple; y esta alma «intelectual» es la que conoce y discierne entre el bien y el mal, y entiende que todas las líneas que son iguales a otra, son iguales entre sí; y sabe que tres es un número impar, y cuatro, un número par; y esta alma solo se encuentra, entre los animales mortales, en los hombres. Otra alma es la «rememorativa», 5 que hace que el hombre se acuerde de aquellas cosas que olvidó. (Esta) tercera alma es la que muestra al hombre en su mente lo que, en cierto momento, está oculto de su presencia, como (cuando) alguien que vive en una ciudad se imagina estar en otra ciudad; y esta alma es la que ve sueños y muchas cosas que son parecidas a las futuras. La cuarta alma es la «excogitativa» de las técnicas, como tejer o urdir y cosas semejantes. Y si tuviéramos oportunidad de prolongar la discusión sobre estas materias, os declararía cómo es cada una de estas almas por sí mismas, sus ventajas y las necesidades de cada una.

2. Pero uno de los sabios presentes, llamado Simas, le respondió:

- Señor y maestro nuestro, siempre nos has hecho bien y nos has enseñado muchas ciencias; ahora también aumenta tu bondad con nosotros y conforta nuestros corazones así como has confortado tu corazón, para que aprendamos a no temer el día de la muerte y no estemos turbados como los demás hombres que se turban de la muerte, pues vemos que los que mueren, en su agonía están en grandísimo temor y agitación ya que ignoran adónde van y lo que sucederá con sus esperanzas; y entonces nos harías dos favores: primero, porque nos darías una enseñanza que conforte nuestro corazón; segundo, porque harías apaciguar las dudas de nuestro corazón sobre ti y nuestros lamentos sobre tu partida de nosotros, porque tu fin será paz y descanso perpetuos. 
Aristóteles le respondió:

—Ea, os enseñaré y dirigiré en la manera cómo entender y conocer la verdad de mis palabras; y aunque tenga gran tribulación, oleré el olor de esta manzana para retomar mis espíritus conmigo, hasta acabar mi exposición, ya que sé que por ello tendré un buen premio, pues entenderéis un asunto tal que no es un asunto vano para vosotros.

Los discípulos se levantaron y cada uno le besó su cabeza. Y les dijo:

-Primeramente os preguntaré si confesáis que creéis en la ciencia de la filosofía, que contiene todas las ciencias, porque es verdadera; y quien la busca, busca la verdad, la rectitud y los pasos $^{6}$ más altos y divinos, y que por ella existe la diferencia entre el hombre y los demás animales.

Ellos dijeron:

—Lo queramos o no, confesamos que así es.

Dijo:

- Si es como decís, el bien que, para el hombre, proviene de las ciencias, y los grandes pasos que (el hombre) adquiere con ellas provienen para el hombre, en este mundo en que estamos hoy o en el otro mundo después de la muerte. Si decís que (provienen) en este mundo en que estamos antes de morir, no habéis dado los pasos convenientes de la ciencia. Ya que muchos hombres ignorantes, que no caminaron por la vía recta ni conocieron a su Creador, acabaron sus días en el bien y (acabaron) sus años conforme a sus deseos; y muchos sabios que se aplicaron mucho a las ciencias y a las especulaciones, aprendieron enseñanzas y conocieron a su Creador, carecen al mismo tiempo de bien y de paz. De igual forma, vosotros, si estáis turbados y teméis la muerte, que es el camino y el recorrido del alma que se separa del cuerpo ignorante para entender los grados divinos y para unirse con las almas sabias y alegres, no dais a la ciencia sus grados ni sus razones sino más bien estáis hundidos en el alma bestial con las otras bestias.

3. Además — dijo Aristóteles — todavía os cuestionaré sobre otro asunto: ¿Sabéis que la muerte no es otra cosa que la separación del alma del cuerpo? 
Dijeron:

-Sí

Les dijo:

— ¿Estáis contentos al entender y aprender la ciencia, y estáis afligidos por no poder aprenderla y entenderla?

Dijeron:

-Sí.

Les dijo:

- Si es como decís, ya veis que el cuerpo ignorante solo ve, oye y entiende mediante la potencia del alma, unida a él en su ser; y el cuerpo, que se deleita en comidas, bebidas y otros placeres contraría al alma para ascender por los grados buenos y rectos para ella, y cuando (el alma) se separa del cuerpo, se separa de lo que es contrario a la perfección de su deseo y de lo que es contrario a su bien. Ya os declaré que el hombre solo puede entender las ciencias nobles por los grados del alma, cuando esta es purgada, perfeccionada y santificada de sus impurezas, cuando se separa de la impureza, que está con ella encarcelada y proviene de la tierra, y no busca los deleites del cuerpo en comidas, bebidas y placeres, a semejanza de los otros animales que no tienen alma inteligente, que hace reprimir sus impulsos y deseos. Por estos grados un hombre es mejor que otro semejante en grado, cuando domina sus impulsos y reprime su naturaleza, tiene horror de los placeres del cuerpo que la ensucian, y más bien busca las delicias del alma con el aprendizaje de las ciencias de Dios — que creó con su sabiduría a su mundo- e investiga sus vías y entiende sus misterios; y entonces se abren los ojos del alma y gozan mucho y se deleitan con deleite diferente de los deleites del cuerpo, porque todos los atractivos del cuerpo acaban y terminan en la nada y destruyen su sustancia y lo hacen descender a la muerte; pero los deleites del alma son entender a su Creador, estudiar las obras de los cielos y su sabiduría, y el recorrido de los astros y sus formas, y (entender) que todo está afirmado y fundado en la sabiduría. Y si en su ciencia no puede abarcar estos grandes grados, que el hombre se estudie a sí mismo, la precisión de sus miembros, cada uno de los nervios que le dan movimiento e impulsan el cuerpo al descanso o al movimiento; las facultades connaturales de todos los miembros que sirven al cuerpo, en 
el que nada se puede ańadir o quitar; y por esto puede conocer en su mente a su Creador y sabrá cuán despreciable es la ciencia del hombre mientras está en vida. Y el alma que desea saber estas ciencias y aprenderlas, es perfecta y recta, y esta alma no se entristecerá ni se turbará cuando se separe del cuerpo, que contraría el logro de su deseo y de su búsqueda.

¿Y no sabéis que el filósofo puro y perfecto mortifica siempre todos sus deseos en este mundo en la comida, en la bebida, en el vestido y en los otros deleites, en los tesoros de oro y plata, y desprecia todos los deleites que lo conducen a la destrucción del cuerpo y del alma? Porque el que se aplica mucho a la comida y a la bebida y usa estos mínimos deleites, en que se deleita solo durante el momento que come, corrompe su cuerpo con enfermedades y tristezas, ya que por la demasiada comida y bebida, se desarrollan humedades que nacen en el cuerpo, de las que derivan la raíz, y la fuerza de la vida. Y una (de ellas) es la sangre, de la que deriva el origen de la vida, y es caliente y húmeda; la segunda es la melancolía, que es fría y seca; la tercera es la cólera, que es caliente y seca; la cuarta es la flema, que es fría y húmeda. Y cualquiera de estas es disminuida, aumentada y alterada en su naturaleza con una comida excesiva y variada. E igualmente el que usa mucho el placer venéreo, envejece su cuerpo y debilita su sustancia. Y el sabio memorioso, que siempre desprecia y odia tales cosas, y perfecciona su alma investigando la ciencia de su Creador, que de la nada hizo el mismo ser, él es quien siempre debe alegrarse en la muerte, que es la separación del alma y del cuerpo. ¿Qué ventaja, pues, tendría él en vivir si siempre mortifica todos los deleites que son despreciables y viles? Más aun, es siempre su deber alegrarse cuando su alma se aproxima a su Creador y se deleita en su resplandor, ya que no teme aproximarse a Él por no encontrar contradictor ni rechazador, ${ }^{7}$ como las almas que han seguido vanidades y no se han aplicado a las ciencias ni han tomado su camino; y ellos son quienes no pueden aproximarse ni alcanzar aquel lugar, pues encuentran contradictor y rechazador. Y vosotros, si sois sabios e inteligentes como decís, que también odiáis todos los deleites del cuerpo así se piensa que hacéis por el camino de las ciencias—, ¿¿de qué os turbáis o qué teméis? Si cogisteis la raíz, amad el fruto.

\section{Respondió Simas:}

- Señor y maestro nuestro, nos has hecho muy amantes de la muerte, que antes temíamos mucho. 


\section{JULIO PICASSO MUÑOZ}

Y después de él, respondió uno de los discípulos, llamado Melión:

- Hasta ahora mucho temía la muerte, y ahora me entristezco y temo por la duración de la vida.

Respondió Caritón y le dijo:

- ¿Por qué te entristeces y temes por la vida y la duración de los días? Ya que si buscas la muerte o la investigas, la encontrarás y no habrá quien te contradiga.

Melión le respondió:

-Esta no es respuesta de varón prudente como tú, ya que si bien no temo la muerte, tampoco la busco antes de que llegue, porque la ventaja del hombre en la vida es para que suba hacia los grados más altos y aprenda las ciencias y tome los caminos de la filosofía, ya que por su medio conocerá a su Creador y (conocerá) que todas las obras tienen un operador, y todo móvil tiene su motor, hasta llegar por su ciencia al primer operador, que de la nada hizo el ser y es el iniciador de todos los inicios y el principio de todos los principios, y que el mundo no puede contenerlo; y el alma ignorante no lo conoce porque su ciencia (de Dios) construyó las esferas y, en todas las esferas, las estrellas brillantes; y les dio el poder de dominar en este mundo inferior y de hacer el bien y también el mal, la muerte y la vida, las riquezas y la pobreza, y todo esto, por virtud del gobernador y rectificador. Y los que contemplan las estrellas y contemplan el dominio de este mundo, dan el poder y el dominio a las estrellas y las hacen dioses y las sirven y las alaban y piensan que todo lo que hacen por sí mismas y por su poder, y que dominan por su poder; y en esto se engañaron los sabios antiguos, quienes hicieron muchas majestades semejantes con las estrellas, a las que servían, y se olvidaron de la raíz, y cada uno adoptaba para sí una de las estrellas como querían: unos, el sol; otros, la luna; otros, otras. Y si hubiera sido así como estos sabios lo entendían y conocían, habría sido necesario que las obras de las estrellas y el curso de ellas no siempre fuesen de una misma forma. Ahora bien, siempre están de una misma manera y no cambian los decretos y recorren su camino según la facultad que se les dio para obrar según su voluntad y sus deseos; y al recorrer ellas para arriba o para abajo, ora de oriente a occidente, ora de occidente a oriente, se mueven según su voluntad, sin contradictor; ya que todas las estrellas juntas son como un siervo a quien se le obliga a hacer una sola cosa y no tienen poder en sí mismos de variar o de mudar, y sus movimientos y recorridos no son por sí mismos ni por virtud de ellos, ya que la esfera superior es la que las hace mover a todas; y 
esta virtud fue dada a la primera esfera por su Creador, como se demostró en el libro de la Filosofía, en el que se analizan todas las ciencias y sus fundamentos.

Y todos los hombres, primero se equivocaban en esto hasta la llegada de Noé, que fue el primero en conocer al Creador de las esferas; y él conoció que cualquier cosa tiene un principio, y que este principio tenía una ciencia y (diferentes) grados: mayor, alto, altísimo. Y después de Noé, nació Abrahán, que fue el más sabio de todos y añadió mucho a lo aprendido y entendió que toda su generación iba al error; y entonces Dios le ordenó inmolar a su único hijo, y quiso con esto hacerlo perfecto para el servicio de Dios; y conoció (Abrahán) que el sol y la luna y todas las estrellas tenían un primer motor, y no siguió el camino de su padre que adoraba los ídolos en Jarán, que eran los ídolos de la luna; y toda la generación sacrificaba a aquellos ídolos y los servía y echaba a sus hijos e hijas al fuego. Y aquel que haya llegado a este grado y entendido en el camino de la sabiduría como lo hizo él, está apto para buscar la muerte, como tú dices. Pero yo no he llegado todavía a este alto grado, por lo que no busco la muerte hasta que venga, porque no es posible, con poca vida, que yo llegue a esta ciencia y a grado tan grande.

Respondió Aristóteles a Caritón:

—Me agrada la respuesta de Melión; sus palabras nos han agradado mucho; respondió la verdad y yo profeso sus palabras y alabo su exposición

5. Uno de los discípulos, de nombre Arastárato, respondió:

-Maestro nuestro, sé más generoso con nosotros y enséñanos cómo aprender más la filosofía que tiene este elevado grado que lleva al hombre de la oscuridad de la ignorancia y de las tinieblas de la estupidez a la luz de la ciencia y a la claridad del intelecto.

Respondió Aristóteles:

-Quien quiere entender la filosofía y quiere ser sabio, lea y aprenda los ocho primeros libros que compilé, hasta llegar al libro Del alma, y de este aprenderá y entenderá en qué parte del cuerpo está la sede del alma y su naturaleza, y si ella está encarcelada en él, o si existe antes que esté con él o si es creada con el cuerpo, o si descansa en él, o si resucitará y se levantará, o por qué se oculta a los ojos de todos los animales después que se separa del cuerpo, o si acabará junto con él. Y cuando medite sobre estos eventos del alma, conocerá a 


\section{JULIO PICASSO MUÑOZ}

su Creador y caminará en la vía recta y no se apartará ni a la derecha ni a la izquierda; y este es el máximo grado y no hay otro más alto. Y yo ya os declaré la vía de la verdad y no me he salido del recto sendero, porque los que enseñan y dan doctrina no deben mentir ni falsear sus palabras. Y sabed que todo aquel que reprime los deseos de su cuerpo y proporciona a su alma la doctrina de la filosofía y conoce sus grados, si temiese o se turbase cuando se separe del cuerpo y cuando le sobrevenga la muerte, esto no sería el resultado de la ciencia perfecta, pues no habría llegado al final de la ciencia de la filosofía: todos los que lo escuchen, lo despreciarán. Mas el que no se aparta de la vía de los sabios, castiga su alma, reprime su naturaleza, confía en su Creador, reprueba el mal, elige el bien y no se asusta de la muerte, está apto para ser llamado sabio y para que se diga que ha llegado al final de la filosofía; mas no aquel que, habiendo entendido la vía de la ciencia, se turba de la muerte cuando el alma se separa del cuerpo, porque ¿qué ventaja tiene la ciencia sin fruto? Por esto siempre conviene que la filosofía se destine a instruir a los ignorantes en aquello que no entendieron con las ciencias y las doctrinas, pues no han conocido a su Creador, y su saber no abarca el bien y el mal, y solo saben del bien y del mal lo que aprendieron de niños; y el que les proporciona la doctrina de la vida de manera buena y recta, este es quien entiende y (ella) permanece firme en su alma y no se diluye ni se cambia; y similarmente aquel que les enseña una vía no recta; pero hay una gran diferencia entre estos y los que tienen la recta vía ${ }^{8}$. Los mencionados primero, aunque estén en el buen camino, son semejantes a las bestias que son conducidos por el freno del hombre en el buen camino; y ellos son los que no aprenden a saber por sí mismos. Y hay otra especie de hombres, cuyos sentidos e intelecto están preparados y capacitados para todo, y ven todo en sus almas

Y hay dos sectas entre ellos: los primeros dicen que el mundo no tiene principio ni fin, y que no hay nada nuevo bajo el sol, sino que una generación se va y otra llega; que la tierra permanece eternamente y no tiene sustentador ni gobernador; y estos son los que niegan la raíz. Los segundos son los que conocen naturalmente, los que dicen que el alma es creada junto con el cuerpo o del cuerpo, y que, mientras el cuerpo existe, también su alma permanece en su ser; y hacen demostración de esta proposición usando el ejemplo del nińo, que, mientras es pequeño y tierno, no recibe las ciencias ni tiene intelecto porque su cuerpo es tierno y húmedo y no ha alcanzado su edad adulta; porque si sucediera que el alma fuese de otra creación que el cuerpo, ${ }^{9}$ ¿por qué el cuerpo impediría que el alma entendiese, máxime cuando, al enfermarse el cuerpo, el alma se enferma y se engaña de tal manera que, 
por la enfermedad del cuerpo, ve y habla cosas falsas y su inteligencia es disminuida? Estos entienden y comprenden la gran ciencia de Dios y sus obras a través de los miembros, la sustancia y los nervios del cuerpo. Y yo ya os declaré, en los libros que he compilado, tales cuestiones, y mostré sus imposibilidades y las destruí según la vía de la verdad de la ciencia.

6. Los escolares asistentes le dijeron:

- Señor y maestro nuestro, enséñanos cuál sea la ciencia recta que el hombre debe aprender y entender, y cómo sube por ella al gran grado de la ciencia de la rectitud.

Aristóteles les respondió:

-Ninguna ciencia es igual a la ciencia de la filosofía, que clarifica el alma y la hace deleitarse en este mundo en la perfección y en la rectitud, que es el principio de su felicidad; y por ella puede comprender y entender el bien del otro mundo, y quien la descubre, descubre la vida en ambos mundos. En efecto, en los ocho primeros libros se encuentran todas las vías de la ciencia, con las que el hombre puede comprender y poseer los principios para las vías de todos los métodos, y conocer sus propios razonamientos, que se aplican racionalmente a los asuntos disputables y aquellos (razonamientos) que no se aplican por carecer de la recta vía por la que se puede conocer algo verdadero. Y estos razonamientos son cercanos de la verdad, pero no son verdaderos ni útiles sino que existen para que, por ellos, se manifieste la audacia del hablante en su ciencia para debilitar las palabras de su interlocutor y para superar las palabras con la fuerza de su ciencia con razones ordenadas y maravillosas, con el objeto de que el interlocutor no tenga capacidad de resistir; y esta ciencia es útil como es útil el escorpión en la triaca ${ }^{10}$ que, aunque sea tóxica, sin embargo si se la da a un paciente, el dolor disminuye y sirve de remedio. Y racionalmente conviene que el filósofo sepa todas estas razones para que no sea engańado sofísticamente ni sea enredado con las palabras y entienda los tópicos y proposiciones con las que se le hacen sofismas; y en estos libros se encuentra la verdad de todas las ciencias que no sean particulares. Y compilé otro cierto libro, llamado Metafísica, y en él declaré que el firmamento superior y las estrellas no pertenecen a las naturalezas que vemos existir debajo de la luna, y pertenecen a otra naturaleza que no tenemos poder ni facultad de conocer y entender. Y de allí, del superior, el alma inteligente se deslizó en el cuerpo; y no se compone de otra naturaleza; más bien, es simple, limpia y pura. ¡Feliz el alma que no está inficionada con las malas obras de este mundo y ha entendido a su Creador, pues ella regresa a su lugar con grandes deleites, no con los deleites 


\section{JULIO PICASSO MUÑOZ}

del cuerpo que son despreciables! ¡Y ay del alma pecadora que no tiene capacidad de poder regresar a su lugar y de poder ascender a su patria porque las torpes obras del deleite corporal le impiden subir!

Y cuando el sabio llegaba al final de estas palabras, empezaron a temblar sus manos, de las que cayó la manzana que sujetaba. Y cuando su rostro empezó a oscurecerse, expiró Los escolares cayeron inclinados sobre él, lo besaron y elevaron juntos un lamento llorando con muchas lágrimas, y dijeron:

-Que aquel que recoge las almas de los filósofos, recoja la tuya y la coloque en sus tesoros, así como es digna de que sea colocada el alma del hombre recto y perfecto como tú eres.

\section{Notas}

${ }^{1}$ Confieso no entender esta frase. Quizá debe entenderse que el hombre, noble, fue creado del barro, innoble. Más adelante se dice que conviene que el hombre se considere «noble e innoble». Puede ser que se refiera a la forma y a la materia del hombre.

${ }^{2}$ La interpretación de esta subiecta coniunx es problemática. Quizá se refiera al cuerpo o a la materia del hombre.

${ }^{3}$ Con el nombre de Honor del Monte Sant'Angelo se conoce la región del monte Gargano, a orillas del Adriático, frente al golfo de Manfredonia, llamado así en honor de Manfredo.

${ }^{4} \mathrm{Me}$ es difícil precisar el sentido de fluxu corporum.

${ }^{5}$ Aristóteles habla del alma sensibilis, intelligibilis o intellectualis, rememorativa y excogitatiua. Por eso pensamos que la tertia anima es la rememorativa. 
${ }^{6}$ Los grados o pasos divinos o de la filosofía o del alma o de la ciencia habrían merecido mayor aclaración.

${ }^{7}$ La expresión anima inuenit contradictorem et repulsorem parece bíblica.

${ }^{8}$ La expresión inter hos et qui habet uiam rectam parece referirse a los que enseñan o no la vía recta. Pero, después, el contexto nos indica que se trata de los que siguen la vía recta sin conocerla y de los que la siguen con juicio propio.

${ }^{9}$ La expresión quod anima esset alterius creationis quam corpus debe quizá referirse a la creación y existencia simultánea del cuerpo y del alma.

${ }^{10}$ La tyriaca debería escribirse theriaca, que es la triaca o teriaca, de la que habla Plinio, entre otros. 